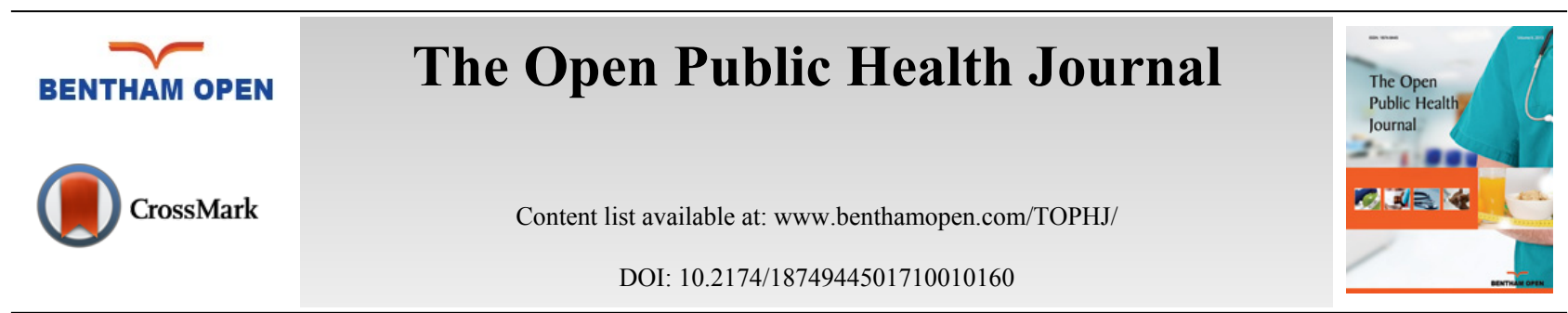

RESEARCH ARTICLE

\title{
Socio-Economic and Demographic Determinants of Under-Five Mortality in Ethiopia, 2011
}

\author{
Frissiano Ernest Honwana ${ }^{*}$ and Sileshi Fanta Melesse \\ University of KwaZulu-Natal - School of Mathematics, Statistics and Computer Science Pietermartzburg, KwaZulu- \\ Natal, South Africa
}

Received: April 28, 2017

Revised: June 01, 2017

Accepted: August 04, 2017

\begin{abstract}
:
Background:

Although the economic conditions in Ethiopian households have recently improved, under-five mortality has remained one of the major problems in the country. Identification of the risk factors for under-five mortality is an important problem that needs to be addressed. This study aimed to estimate the effect of socio-economic and demographic factors on under-five mortality in Ethiopia.

\section{Methods:}

Data consisting of a nationally representative sample of 26370 children in the 2011 Ethiopia Demographic and Health Survey was analyzed. The survey logistic regression model was adopted for analysis. The outcome variable was the child's survival status i.e. the child being either alive or dead. The explanatory variables were the socio-economic and demographic factors for mother and child, respectively.
\end{abstract}

\section{Results:}

The overall significance of all variables was investigated, and the following variables were found to have significant effect on the under-five mortality in Ethiopia: the sex of child, mother's age at birth, the region, area of residence and educational of the mother.

\section{Conclusion:}

This study suggests that improving the educational level of mothers and reducing the regional disparity can reduce child mortality in Ethiopia.

Keywords: Under-five mortality, Odds ratio, Logistic regression, Survey logistic regression.

\section{INTRODUCTION}

Many developing countries all over the world experience a high number of deaths among children below the age of five (under-five mortality). Under-five mortality is largely related to the quality of life and the well-being of a population. It is one of the serious issues facing not only Sub-Saharan Africa regions, but also many countries throughout the world. This shows the importance of interventions to reduce the rates of under-five mortality. Due to increasing under-five mortality rates, there have been efforts made to solve this issue facing the world. One of them is the Millennium Development Goal 4 (MDG 4), which aimed to reduce under-five mortality rates by two-thirds between 1990 and 2015 [1]. Because of the MDG 4, the Ethiopian government had also pledged to reach MDG 4 by 2015.

According to Central Statistical Agency (Ethiopia) and ICF International (2012), Ethiopia is one of the few African

\footnotetext{
* Address correspondence to this author at the University of KwaZulu-Natal - School of Mathematics, Statistics and Computer Science Pietermartzburg, KwaZulu-Natal, South Africa; Tel: +27733354148; E-mail: honwana@ymail.com
} 
countries that have made considerable progress in reducing under five mortality, however the problem still needs due consideration.

There has been a major decrease in under-five mortality worldwide over the recent years, decreasing from 90 in 1990 to 46 deaths per 1000 live births in 2013 [2]. Although this is an admirable achievement, proper actions must be taken to prevent the under-five mortality that is still affecting many countries in the Sub-Saharan Africa and South Asia regions. Although the Sub-Saharan Africa regions have high rates of under-five mortality compared with the rest of the world, it has seen a faster decline in its under-five mortality rate, dropping from 177 in 1990 to 98 in 2012 per 1000 live births [3]. Ethiopia is one of the Sub-Saharan African countries located in Eastern Africa. According to Central Statistical Agency (Ethiopia) and ICF International (2012), under-five mortality rates have decreased by $47 \%$ over the 15 -year period preceding the survey, dropping from 166 to 88 deaths per 1000 live births. Because of the elevated levels of under-five mortality rates, it is evident from the Ethiopia Demographic and Health Survey (EDHS) data that Ethiopia's current levels of under-five mortality are still high compared to the MDG 4's 2015 levels. This shows that Ethiopia is one of the countries in the Sub-Saharan Africa region that are still experiencing high levels of under-five mortality. According to Central Statistical Agency (Ethiopia) and ICF International (2012), the under-five mortality rates were higher in rural areas than in urban areas. Moreover, the mortality rates were the highest in BenishangulGumuz and lowest in Addis Ababa, probably due to the high level of urbanization in Addis Ababa. These inequalities in under-five mortality among rural and urban areas in Ethiopia are due to various factors. These factors include better education in urban areas, access to better hospital infrastructure, high income earners and other health conditions that are more advantageous for people living in urban areas than those in rural areas. Demographic factors like the age of the mother at birth of the child are believed to influence the health of the child. Children born from older mothers and children born from teenage mothers have higher mortality rates. This is attributed to the biological reproductive maturity. Birth complications are often recorded for aged mothers, resulting in children with severe health conditions. Teenage mothers are usually not experienced enough to take care of their infants [4]. Sinha et al. [5] showed that children under-five born from mothers in the age group less than 19 years old have a higher hazard rate of death (1.68 times) as compared to mothers aged 20 to 24 years.

Determining socio-economic and demographic factors of under-five mortality in Ethiopia is an important study, necessary for future planning of health care interventions, especially for achieving MDG 4. Between 1990 and 2015, the under-five mortality rates have declined by more than half [6]. This implies that the MDG 4 target of reducing underfive mortality rates by two-thirds, between 1990 and 2015 was not achieved. In addition, 5.9 million children under the age of five died in 2015, most likely from preventable causes [6]. As a result, the world implemented Sustainable Development Goals (SDGs) for 2016-2030, to likely carry-out unfinished agenda that was targeted by the 2015 MDGs. As mentioned by Kumar et al. [7], SDGs exhibit continuity and reinforcement of the MDGs while making these more sustainable by enhancing environmental goals. Moreover, SDGs benefit from the important lessons obtained from the MDGs. As a result, the world is now focusing on achieving Sustainable Development Goal 3 (SDG 3) instead of the MDG 4. Therefore, this study is important in relation to MDG 4 and hence it will more likely help in achieving SDG 3, which intends to ensure health and well-being for all in all ages [6].

Mosley et al. [8] analytic framework for the study of child survival determinants in developing countries was used by various researchers to investigate the determinants of under-five mortality. According to Mosley et al. [8], 14 biomedical factors (proximate determinants) were found and grouped into five categories: availability of nutrients factors, personal illness factors, maternal factors, environmental-sanitation, and injury factors. However, personal illnesses, availability of nutrients and injury factors have not been considered in this study. Many researchers found that maternal education had a statistically significant effect on under-five mortality. For instance, Desai et al. [9] used the first round data of the Demographic and Health Surveys of 22 developing countries, and found that mothers' education was highly associated with under-five mortality in several countries, as it increases the awareness of health care practices. Other factors found by several researchers to affect under-five mortality include households' socio-economic and environmental characteristics. Ayele et al. [10] used a structured additive logistic regression model to estimate the determinants of under-five mortality in Ethiopia and found that lower child mortality is associated with greater household wealth and that children from older mothers have less chance of dying than the ones from younger mothers. Furthermore, Ezeh et al. [11] used the Nigeria Demographic and Health Surveys for the years 2003, 2008 and 2013, fitted the cox regression model, and found that poor households, living in rural areas and with no formal education for mothers, had a significant impact on Nigerian children. Similar findings were reported in the study by Susuman [12], using the 2000 \& 2005 EDHS data to identify determinants of under-five mortality in Ethiopia. This study found that 
rural areas and poor households were the most common factors of child mortality in Ethiopia. Therefore, based on the existing literature, the major proximate determinants of infant and under-five mortality can be categorized into three groups: mother, child, and household characteristics [13]. However, most the above studies used the time to event approach in the analysis of child survival. Most of the approaches also ignored the complexity of the survey design. This paper tries to use a different approach which is the analysis of the event itself. This study uses the survey logistic regression analysis to identify socio-economic and demographic factors associated with under-five mortality in Ethiopia.

\section{METHODS}

This study used the 2011 EDHS carried out by the Ethiopia's Central Statistical Agency (CSA). This survey is the third EDHS, with the first and second surveys implemented in 2000 and 2005, respectively. It is a cross-sectional investigation conducted at household level. The goal of the 2011 EDHS was to provide estimates of health and demographic variables at country level as well as at regional administrative levels. The survey employs the 2007 population and housing census frame as its sampling frame and comprises 624 selected enumeration areas (EAs). Of the total 624 EAs selected, 187 are in urban areas while 437 are in rural areas. Stratified sample selected in two stages was used in the sample for the EDHS. Separation of each region into urban and rural areas was used to achieve stratification. As reported by the Central Statistical Agency (Ethiopia) and ICF International (2012), the sample for EDHS had 23 sampling strata; in each sampling stratum, two-stage selection was used to select sample points. Moreover, sample weights were calculated to ensure effective representatives of the survey results at the regional and national level. A sample of 17817 households was selected nationally for the survey. From these households, women in the 15-49 age group who were available at the day before the survey or who were usual residents were eligible for the survey. According to Central Statistical Agency (Ethiopia) and ICF International (2012), a total of 17385 eligible women from these selected households were identified for the interviews, where the birth history and childbearing experience for each woman were recorded. Furthermore, the data consist of 26370 children from these 17385 eligible women, between birth and fifth birthday, five years preceding the 2011 EDHS.

The outcome of interest in this study is under-five mortality, which is binary (the child is either 'alive or dead'). The independent variables from the EDHS are grouped into two: socio-economic factors and demographic factors. The socio-economic factors included in this study are the mother's marital status, wealth index, area of residence (rural or urban), region of residence, religion and educational attainment. There are five categories of the religion: Orthodox, Catholic, Muslim, Others and Protestant. The mother's marital status has been categorized into two: married and living with a partner. There are three categories of the wealth index: poor, middle and rich. The educational attainment of the mother has been categorized into two: no education and educated. Demographic factors included in this study are the sex of a child and the mother's age at birth of the child. The mother's age has been categorized into seven 5-year age groups starting from the 15-19 (youngest) to the 45-49 (oldest) age groups.

Logistic regression models are useful to assess the effects of covariates on the probability of under-five deaths for data obtained by a simple random sampling procedure. However, using logistic regression for complex survey data can lead to the computation of statistically invalid estimates for the confidence intervals, p-values, and standard errors [14]. Therefore, for our analysis of data from a complex survey design, we used a survey logistic regression incorporating weights, stratification, and clustering of the data [14 - 19].

To estimate the socio-economic and demographic factors on under-five mortality, the analysis was performed using SAS 9.3, procedure proc survey logistic.

\section{RESULTS}

The study contains a total of 26370 children, $51.41 \%$ males and $48.59 \%$ females. These children were from 17385 eligible women, between birth and fifth birthday, five years preceding the 2011 EDHS. More than three-fourths of the children were living in rural areas (85.63\%) while the remaining $14.37 \%$ of the children were living in urban areas. About $46.87 \%$ of the children were poor, as shown in Table 1. Age of most of the mother when the child was born were in the age group 35-39 with a percentage of 23.16\%, while much fewer mothers were in the age group 15-19 with a percentage of $1.25 \%$. According to Table 1, most of the children's mothers were married $(95.44 \%)$ when the survey was performed. About $76.36 \%$ had an uneducated mother during the survey. Many children had mothers that were Muslim (42.51\%), followed by Orthodox (35.34\%) and Protestant (19.16\%). The regional distributions of sampled children show that children came from the Oromiya region $(16.37 \%), 15.57 \%$ from the Southern Nations, Nationalities, and 
Peoples' (SNNP) region and the Amhara (15.62\%) region. These three regions contributed the largest percentage of mothers in the sample.

Table 1. Distribution of children in the 2011 EDHS Data.

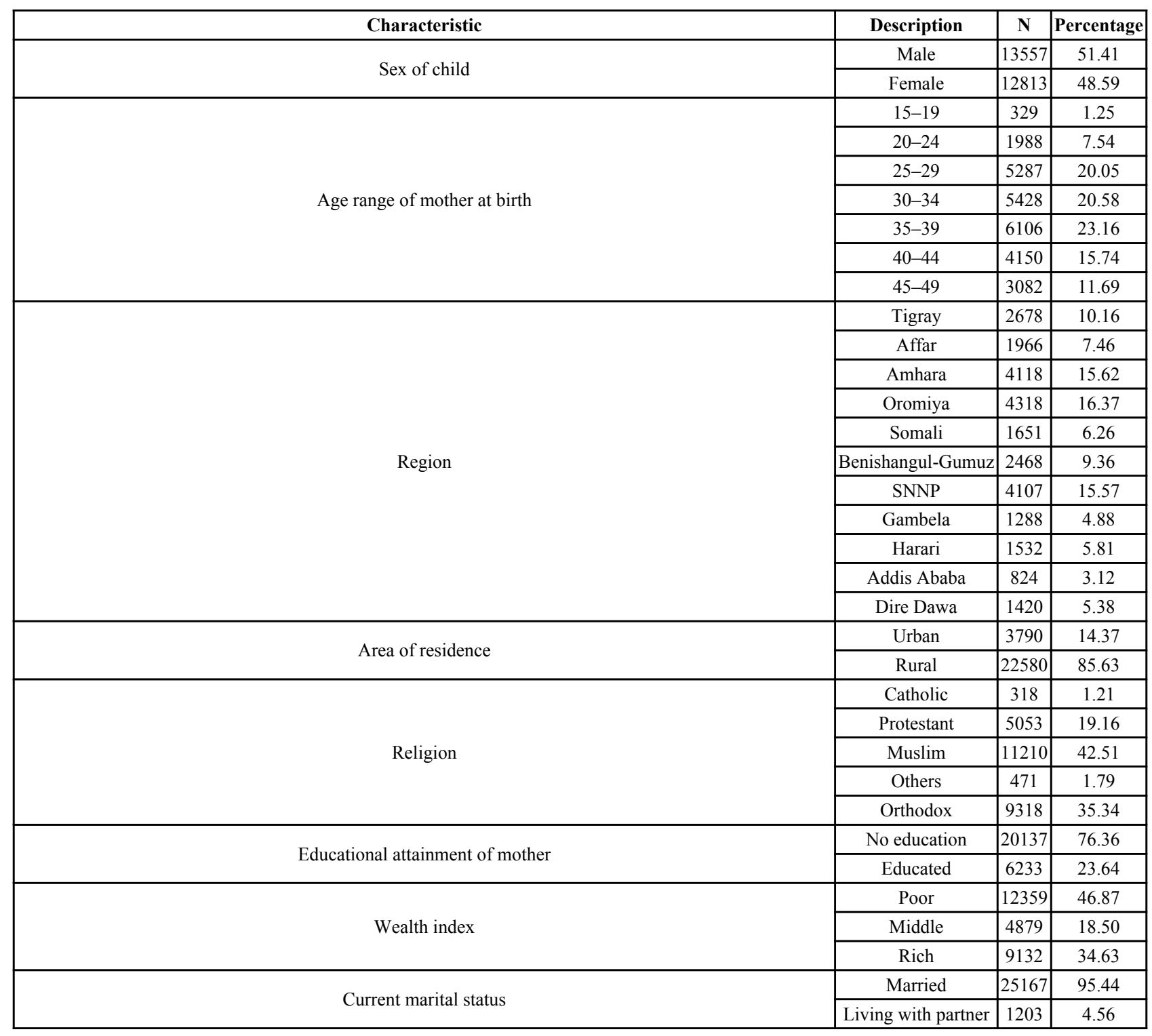

When all the variables presented in Table 1, were subjected to survey logistic regression analysis, model reduction was performed, where the significance of potential factors was investigated. Consequently, several variables were found to be statistically significant in predicting the probability of under-five deaths. Table 2 presents the survey logistic regression analysis, only containing significant parameter estimates associated with each socio-economic and demographic factor, together with the estimates of the odds ratios (OR). The relationship between the probability of under-five mortality and the socio-economic and demographic factors was explored using odds ratios.

Female children under the age of five had $20 \%$ lower odds of death (Table 2$)$ than male children $(\mathrm{OR}=0.800,95 \%$ CI: $0.720,0.890)$. Furthermore, the odds of under-five mortality increased with the mother's age, from the 20-24 to 45-49 age group compared with 30-34 age group. In addition, children under the age of five who live in Gambela region had $83.6 \%$ higher odds of death than those in Tigray $(\mathrm{OR}=1.836,95 \% \mathrm{CI}: 1.320,2.555)$, followed by those from Benishangul-Gumuz $(\mathrm{OR}=1.720,95 \% \mathrm{CI}: 1.397,2.117)$ and Affar region $(\mathrm{OR}=1.404,95 \% \mathrm{CI}: 1.076,1.831)$. On the other hand, children below the age of five living in rural areas had $45.2 \%$ higher odds of death than those from urban areas $(\mathrm{OR}=1.452,95 \% \mathrm{CI}: 1.075,961)$. Furthermore, children under the age of five from uneducated mothers had $51.4 \%$ higher odds of death than those with educated mothers (OR $=1.514,95 \% \mathrm{CI}: 1.301,1.762)$. 
Table 2. Output of the Survey logistic regression analysis.

\begin{tabular}{|c|c|c|c|c|c|c|}
\hline \multicolumn{4}{|c|}{ Analysis of Maximum Likelihood Estimates } & \multicolumn{3}{|c|}{ Odds Ratio } \\
\hline \multirow{2}{*}{$\begin{array}{c}\text { Parameter } \\
\text { Sex of child (Male=reference }\end{array}$} & \multirow[t]{2}{*}{ Estimate } & \multirow[t]{2}{*}{ Std Error } & \multirow[t]{2}{*}{ P-value } & \multirow[t]{2}{*}{ Estimate } & \multicolumn{2}{|c|}{$\begin{array}{c}95 \% \text { Confidence } \\
\text { Interval }\end{array}$} \\
\hline & & & & & & \\
\hline Female & -0.2227 & 0.0541 & $<.0001$ & 0.800 & 0.720 & 0.890 \\
\hline \multicolumn{7}{|c|}{ Age range of mother at birth (30-34=reference) } \\
\hline $15-19$ & -0.4363 & 0.2703 & 0.1065 & 0.646 & 0.381 & 1.098 \\
\hline $20-24$ & -0.3998 & 0.1280 & 0.0018 & 0.670 & 0.522 & 0.862 \\
\hline $25-29$ & -0.2893 & 0.0946 & 0.0022 & 0.749 & 0.622 & 0.901 \\
\hline $35-39$ & 0.2067 & 0.0812 & 0.0109 & 1.230 & 1.049 & 1.442 \\
\hline $40-44$ & 0.2465 & 0.0872 & 0.0047 & 1.279 & 1.079 & 1.518 \\
\hline $45-49$ & 0.4808 & 0.0880 & $<.0001$ & 1.617 & 1.361 & 1.922 \\
\hline \multicolumn{7}{|l|}{ Region (Tigray=reference) } \\
\hline Addis Ababa & -0.3546 & 0.2205 & 0.1078 & 0.701 & 0.455 & 1.081 \\
\hline Affar & 0.3391 & 0.1356 & 0.0124 & 1.404 & 1.076 & 1.831 \\
\hline Amhara & 0.1451 & 0.1000 & 0.1465 & 1.156 & 0.950 & 1.406 \\
\hline Benishangul-Gumuz & 0.5422 & 0.1060 & $<.0001$ & 1.720 & 1.397 & 2.117 \\
\hline Dire Dawa & 0.2420 & 0.1382 & 0.0799 & 1.274 & 0.972 & 1.670 \\
\hline Gambela & 0.6076 & 0.1686 & 0.0003 & 1.836 & 1.320 & 2.555 \\
\hline Harari & 0.0603 & 0.1599 & 0.7061 & 1.062 & 0.776 & 1.453 \\
\hline Oromiya & 0.1560 & 0.0978 & 0.1105 & 1.169 & 0.965 & 1.416 \\
\hline SNNP & 0.1883 & 0.0975 & 0.0535 & 1.207 & 0.997 & 1.462 \\
\hline $\begin{array}{r}\text { Somali } \\
\end{array}$ & 0.1570 & 0.1232 & 0.2026 & 1.170 & 0.919 & 1.490 \\
\hline \multicolumn{7}{|c|}{ Area of residence (Urban=reference) } \\
\hline Rural & 0.3729 & 0.1533 & 0.0150 & 1.452 & 1.075 & 1.961 \\
\hline \multicolumn{7}{|c|}{ Educational attainment of mother (Educated=reference) } \\
\hline No education & 0.4146 & 0.0775 & $<.0001$ & 1.514 & 1.301 & 1.762 \\
\hline
\end{tabular}

*Likelihood Ratio (LR) test $=575097338$, p-value $<0.0001$; Score test $=547591762$, p-value $<0.0001$; Wald test $=263.97$, p-value $<0.0001$ *

The value of the likelihood ratio (LR) test statistic for the overall significance of the survey logistic regression model is 575097338 with a $(p<0.0001)$, which implies that the overall fitted model is significant. This result indicates that at least one of the parameters is significantly different from zero. The score and the Wald tests are also in favour of the overall significance of the fitted survey logistic regression model $(p<0.0001)$.

\section{DISCUSSION}

The 2011 Ethiopian Demographic and Health Survey data was used, where the survey logistic regression model was adopted to estimate the effect of socio-economic and demographic factors on under-five mortality in Ethiopia. The analysis from this model has shown that the sex of child, mother's age at birth, the region, area of residence and educational of the mother have significant associations with under-five mortality. Several studies [11, 20] stated that babies of relatively young mothers have higher chances of under-five mortality. However, the survey logistic regression analysis in this study has shown that the chances of under-five mortality increases with mothers' age (from 20-24 to 45-49 age groups). This indicates that babies of relatively old mothers have a higher probability of under-five mortality. This may be due to various reasons. Poor mothers at the age of 20 and above may have more children (i.e. a larger family size). As a result, there may be a smaller share of scarce resources to meet the requirements of growing children. This may affect the younger ones, and hence mortality chances might be higher for the younger children under five years of age. Furthermore, the survey logistic analysis has shown that children from the Affar, Benishangul-Gumuz and Gambela regions were at a higher risk of under-five mortality. The standard of living and access of public sectors in these regions may have a significant effect on under-five mortality. This study has unambiguously shown the existence of disparity among the regions of Ethiopia, with a relatively less developed region being seriously affected by underfive mortality. Moreover, children under the age of five from rural areas were at a higher risk of experiencing death than those from urban areas. The survey logistic analysis showed that female children had lower odds of under-five mortality than males. This may be due to biological factors [11]. According to Alonso et al. [21] study on causes of neonatal mortality in Spain for example, the lower odds for females under-five may be due to late lung maturity resulting in 
respiratory weakness in male children compared to females. Moreover, children with uneducated mothers had higher probabilities of under-five mortality than children with educated mothers. There are some explanations that can be made about the influence of education on under-five mortality. Educated mothers are more likely to adopt alternatives in child care and recent treatments, and are more likely to reside in places that have well-equipped medical facilities and good sanitation infrastructure [11]. These findings were also supported by [9, 13, 20]. In addition, the LR test, the score and the Wald tests were in favour of the overall significance of the fitted survey logistic regression model.

The identified factors will assist policy makers to understand the areas they need to focus on, in order to enhance the planning and evaluation of health policies to prevent under-five mortality in Ethiopia. Our findings in this study are supported by several researchers' findings studying the determinants of under-five mortality in several countries, including Ethiopia. These include [9 - 13, 20].

\section{CONCLUSION}

This study supports the hypothesis that under-five mortality is still an issue in Ethiopia. The results from the survey logistic regression analysis suggested that living in Benishangul-Gumuz, Gambela and Affar regions, child being a male, living in rural areas, having mothers above 19 years of age groups, and having mothers with no education were common significant determinants for under-five mortality in Ethiopia. Even though some socio-economic and demographic factors of interest in the study indicated no significant association with under-five mortality, it would be misleading to conclude that factors such as wealth index, religion and current marital status of mother have no significant effect on child survival. Therefore, interventions that focus on mothers living in rural areas, mothers in Benishangul-Gumuz, Affar and Gambela, and uneducated mothers are required for improving child survival in Ethiopia. Further research is required to enable an understanding of the distribution of under-five mortality across all the different regions in Ethiopia.

\section{ETHICS APPROVAL AND CONSENT TO PARTICIPATE}

Not applicable.

\section{HUMAN AND ANIMAL RIGHTS}

No Animals/Humans were used for studies that are base of this research.

\section{CONSENT FOR PUBLICATION}

Not applicable.

\section{CONFLICT OF INTEREST}

The authors declare no conflict of interest, financial or otherwise.

\section{ACKNOWLEDGEMENTS}

Declared none.

\section{REFERENCES}

[1] United Nations The Millennium Development Goals Report, New York 2010. Available at: https://www.un.org/development/desa/publications/millennium-development-goals-report-2010.html

[2] UNICEF WHO, World Bank, UN-DESA Population Division Levels and Trends in Child Mortality 2014 New York 2014. Available at: http://www.who.int/maternal_child_adolescent/documents/levels_trends_child_mortality_2014/en/

[3] United Nations The Millennium Development Goals Report 2012 New York $2012 . \quad$ Available at: https://www.un.org/development/desa/publications/mdg-report-2012.html

[4] Kibet MK. Comparative study of infant and child mortality: The case of Kenya and South Africa. African Population Studies 2010; 24(1-2): $1-25$.

[5] Sinha S, Aggarwal AR, Osmond C, Fall CH, et al. Maternal age at childbirth and perinatal and under-five mortality in a prospective birth cohort from Delhi. Indian Pediatr 2016; 53(10): 871-7.

[http://dx.doi.org/10.1007/s13312-016-0950-9] [PMID: 27484448]

[6] United Nations The Sustainable Development Goals Report 2016 New York 2016. Available at: https://unstats.un.org/sdgs/report/ 2016/The\%20Sustainable\%20Development\%20Goals\%20Report\%202016.pdf 
[7] Kumar S, Kumar N, Vivekadhish S. Millennium development goals (MDGS) to sustainable development goals (SDGS): Addressing unfinished agenda and strengthening sustainable development and partnership. Indian journal of community medicine. Official publication of Indian Association of Preventive and Soc Med (Soc Med Publ Group) 2016; 41(1): 1.

[8] Mosley WH, Chen LC. An analytical framework for the study of child survival in developing countries. Popul Dev Rev 1984; 10: 25-45. [http://dx.doi.org/10.2307/2807954]

[9] Desai S, Alva S. Maternal education and child health: is there a strong causal relationship? Demography 1998; 35(1): 71-81. [http://dx.doi.org/10.2307/3004028] [PMID: 9512911]

[10] Ayele DG, Zewotir TT, Mwambi HG. Structured additive regression models with spatial correlation to estimate under-five mortality risk factors in Ethiopia. BMC Public Health 2015; 15(1): 268. [http://dx.doi.org/10.1186/s12889-015-1602-z] [PMID: 25884813]

[11] Ezeh OK, Agho KE, Dibley MJ, Hall JJ, Page AN. Risk factors for postneonatal, infant, child and under-5 mortality in Nigeria: a pooled cross-sectional analysis. BMJ Open 2015; 5(3): e006779. [http://dx.doi.org/10.1136/bmjopen-2014-006779] [PMID: 25818271]

[12] Susuman AS. Child mortality rate in Ethiopia. Iran J Public Health 2012; 41(3): 9-19. [PMID: 23113145]

[13] Negera A, Abelti G, Bogale T, Gebreselassie T, Pearson R. An analysis of the trends, differentials and key proximate determinants of infant and under-five mortality in Ethiopia. Calverton, Maryland, USA: ICF International 2013.

[14] Vittinghoff E, Glidden DV, Shiboski SC, McCulloch CE. Regression Methods in Biostatistics: Linear, Logistic, Survival, and Repeated Measures Models. New York: Springer 2006.

[15] Binder DA, Roberts GR. Design-based and model-based methods for estimating model parameters. In: Chambers RL, Skinner CJ, Eds. Analysis of Survey Data. New York: John Willey \& Sons 2003. [http://dx.doi.org/10.1002/0470867205.ch3]

[16] Mukhopadhyay P. Complex Surveys: Analysis of Categorical Data. Singapore: Springer 2016. [http://dx.doi.org/10.1007/978-981-10-0871-9]

[17] Agresti A. An introduction to Categorical Data Analysis. New York: John Wiley \& Sons 1996.

[18] Moeti A. Factors affecting the health status of the people of Lesotho. South Africa: University of KwaZulu Natal 2007. Masters Thesis [cited 2015 April 23] Available at: http://hdl.handle.net/10413/179

[19] An AB. editor Performing logistic regression on survey data with the new SURVEYLOGISTIC procedure Proceedings of the twenty-seventh annual SAS ${ }^{\circledR}$ users group international conference; 2002. SAS Institute Inc. Cary, NC.

[20] Chowdhury AH. Determinants of under-five mortality in Bangladesh. Open J Stat 2013; 3(3): 213-9. [http://dx.doi.org/10.4236/ojs.2013.33024]

[21] Alonso V, Fuster V, Luna F. Causes of neonatal mortality in Spain (1975-98): Influence of sex, rural-urban residence and age at death. J Biosoc Sci 2006; 38(4): 537-51. [http://dx.doi.org/10.1017/S0021932005026957] [PMID: 16762089]

\section{2017 Honwana and Melesse.}

This is an open access article distributed under the terms of the Creative Commons Attribution 4.0 International Public License (CC-BY 4.0), a copy of which is available at: https://creativecommons.org/licenses/by/4.0/legalcode. This license permits unrestricted use, distribution, and reproduction in any medium, provided the original author and source are credited. 